\title{
RALEIO QUÍMICO EM MACIEIRAS 'FUJI SUPREMA' E 'LISGALA'
}

\author{
JOSÉ LUIZ PETRI ${ }^{2}$, FERNANDO JOSÉ HAWERROTH³, \\ GABRIEL BERENHAUSER LEITE ${ }^{4}$, MARCELO COUTO ${ }^{4}$
}

RESUMO - O raleio químico é uma prática viável na cultura da macieira, pois permite ser realizada em curto período de tempo, reduzindo o custo de mão de obra em relação ao raleio manual. Trabalhos realizados nas principais regiões produtoras de maçãs mostram os benefícios do uso da 6-benziladenina (BA) no raleio químico. A realização de estudos com esta substância é fundamental para o aperfeiçoamento do raleio químico e posterior uso pelo setor produtivo da maçã no Brasil. Neste sentido, foram realizados quatro experimentos, objetivando avaliar a resposta da aplicação de BA, isolada ou em mistura com carbaryl e Promalin $\AA$, em diferentes épocas e concentrações, no raleio de macieiras 'Fuji Suprema' e 'Lisgala'. A aplicação de BA em maiores concentrações é efetiva no raleio de macieiras 'Fuji Suprema' e 'Lisgala'. Há uma redução na efetividade da aplicação de benziladenina em frutos com diâmetro superior a $10 \mathrm{~mm}$. A concentração de BA pode ser diminuída pelo uso do carbaryl, sem comprometimento do efeito raleante.

Termos para indexação: Malus domestica, fitorreguladores, citocininas, qualidade de fruto.

\section{CHEMICAL THINNING OF 'FUJI SUPREMA’AND 'LISGALA'APPLES}

ABSTRACT - The chemical thinning is a viable alternative in apple orchards, because it may be done in a short period of time, reducing the labor in relation to hand thinning. Studies carried out in major apple producing regions show the benefits of using 6-benzyladenine (BA) in chemical thinning. The studies with this substance are essential for improvement of chemical thinning and subsequent use by apple producers in Brazil. In this sense, four experiments were carried out to evaluate the BA application response, alone or in mixture with carbaryl and Promalin ${ }^{\circledR}$, at different times and concentrations on thinning of 'Fuji Suprema' and 'Lisgala' apples. BA applications at higher concentrations are effective in thinning 'Fuji Suprema' and 'Lisgala' apples. There is an effectiveness reduction when BA is sprayed on fruits larger than $10 \mathrm{~mm}$ in diameter. The BA concentration may be reduced by mixture with carbaryl without reduction of chemical thinning effect.

Index terms: Malus domestica, plant growth regulators, cytokinins, fruit quality.

\section{INTRODUÇÃO}

A prática de raleio da cultura da macieira tem como finalidade melhorar o tamanho e a qualidade dos frutos, além de evitar a alternância de produção pela retirada da carga excessiva de frutos antes da transformação floral para o ano seguinte. Em anos de floração abundante e com condições ambientais favoráveis à polinização, a frutificação efetiva pode ser excessiva, necessitando da retirada de parte do excesso de produção para a obtenção de frutos de maior calibre e, consequentemente, de maior valor comercial.

Dentre os métodos disponíveis para efetuar o raleio, o raleio químico pode apresentar vantagens por ser uma operação rápida e permitir ralear flores e frutos no momento adequado (COSTA et al., 2006). Atualmente, a realização do raleio químico na cultura da macieira é uma alternativa viável, pois permite realizar o raleio em um curto período de tempo, com redução de mão de obra, quando comparado ao raleio manual (DENNIS, 2002; GREENE, 2002). Em cultivares que apresentam fixação de quatro ou mais frutos por inflorescência com pedúnculos curtos, como a cultivar Fuji, o uso de raleantes químicos também se mostra vantajoso por facilitar a execução do raleio.

Entre os raleantes químicos para a cultura da macieira, destacam-se o ácido naftaleno acético (ANA), o carbaryl e, mais recentemente, a 6-benzi-

\footnotetext{
'(Trabalho 173-12). Recebido em: 25-05-2012. Aceito para publicação em: 18-10-2012.

${ }^{2}$ Eng. Agr., MSc., Epagri - Estação Experimental de Caçador, Rua Abílio Franco, 1500, Bom Sucesso, C.P. 591, 89500-000, Caçador-SC. E-mail: petri@epagri.sc.gov.br

${ }^{3}$ Eng. Agr., Dr., Embrapa Agroindústria Tropical, Rua Doutora Sara Mesquita, 2270, Planalto do Pici, 60511-110, Fortaleza-CE. E-mail: fernando.hawerroth@embrapa.br

${ }^{4}$ Eng. Agr., Dr., Epagri - Estação Experimental de Caçador, Rua Abílio Franco, 1500, Bom Sucesso, C.P. 591, 89500-000, Caçador-SC. E-mails: gabriel@epagri.sc.gov.br, marcelocouto@epagri.sc.gov.br
} 
ladenina (BA). Segundo Petri et al. (2006), a BA é uma alternativa eficiente para programas de raleio de macieira em regiões de clima ameno. A BA é considerada um bom raleante porque a substância possui baixo perfil toxicológico (YUAN; GREENE, 2000), proporciona aumento do tamanho dos frutos pelo efeito raleante, além de promover aumento no tamanho dos frutos por ser um composto do grupo das citocininas, atuando no aumento da divisão celular. Por esse aumento na divisão celular, segundo Greene (2005), a BA pode aumentar o tamanho do fruto mesmo na ausência de raleio.

Devido às condições climáticas da região Sul do Brasil, a frutificação efetiva de ano para ano é muito variável, fazendo com que a avaliação da necessidade e da intensidade de raleio só possa ser realizada após a fecundação, tornando o raleio químico na floração uma prática de maior risco para o produtor. Segundo Meland (2004), o raleio químico em pós-floração permite a avaliação mais precisa da frutificação efetiva e da real necessidade de aplicação de raleantes químicos. Segundo Robinson e Lakso (2004), os principais fatores que afetam a resposta dos raleantes químicos são a concentração de substâncias utilizadas, a temperatura, a luz e o diâmetro dos frutos. Além disso, o efeito dos raleantes químicos é dependente da interação entre genótipo e condições climáticas, devendo, deste modo, ser testado em cada região produtora.

O objetivo deste estudo foi avaliar a resposta da aplicação de BA, isolada ou em mistura com carbaryl e Promalin ${ }^{\circledR}\left(\mathrm{GA}_{4+7}\right)$, em diferentes épocas, no raleio de macieiras 'Fuji Suprema' e 'Lisgala'.

\section{MATERIAL E MÉTODOS}

Foram realizados quatro experimentos, avaliando-se diferentes tratamentos de raleio, em macieiras 'Fuji Suprema' e 'Lisgala', durante o ciclo de 2009/2010. O experimento 1 foi realizado em pomar comercial localizado no município de Fraiburgo-SC (Lat $27^{\circ} 04^{\prime} \mathrm{S}$, Long $50^{\circ} 52^{\prime} \mathrm{W}$ ), enquanto os demais foram conduzidos em pomares experimentais localizados em Caçador-SC (Lat 26 $50^{\circ} \mathrm{S}$, Long 50 50' W). Ambos os pomares utilizados foram conduzidos em sistema líder central e manejados de acordo com recomendações do sistema de produção da macieira (EPAGRI, 2006).

Experimento 1. Avaliação de raleantes químicos em macieiras 'Fuji Suprema'/ Marubakaido/M-9

Foram utilizadas macieiras da cultivar Fuji Suprema/Marubakaido/M-9, com densidade de plantio de 2.500 plantas ha-1 ${ }^{-}$O delineamento experimental utilizado foi em blocos casualizados, com seis repetições compostas de uma planta, sendo avaliados os seguintes tratamentos: 1) raleio manual com frutos entre $15 \mathrm{~mm}$ a $20 \mathrm{~mm}$ de diâmetro; 2) 6-benziladenina (BA) a $80 \mathrm{mg} \mathrm{L}^{-1}$ em frutos com 5 $\mathrm{mm}$ a $8 \mathrm{~mm}$ de diâmetro; 3) $\mathrm{BA} 80 \mathrm{mg} \mathrm{L}^{-1} \mathrm{em}$ frutos com $10 \mathrm{~mm}$ a $15 \mathrm{~mm}$ de diâmetro; 4) BA $120 \mathrm{mg} \mathrm{L}^{-1}$ em frutos com $5 \mathrm{~mm}$ a $8 \mathrm{~mm}$ de diâmetro; 5) BA 120 $\mathrm{mg} \mathrm{L}^{-1} \mathrm{em}$ frutos com $10 \mathrm{~mm}$ a $15 \mathrm{~mm}$ de diâmetro; 6) BA $80 \mathrm{mg} \mathrm{L}^{-1}+$ carbaryl $1.000 \mathrm{mg} \mathrm{L}^{-1} \mathrm{em}$ frutos com $10 \mathrm{~mm}$ a $15 \mathrm{~mm}$ de diâmetro; 7) BA $120 \mathrm{mg} \mathrm{L}^{-1}$ + carbaryl $1.000 \mathrm{mg} \mathrm{L}^{-1} \mathrm{em}$ frutos com $10 \mathrm{~mm}$ a 15 mm de diâmetro; 8) BA $120 \mathrm{mg} \mathrm{L}^{-1}+$ carbaryl 1.000 $\mathrm{mg} \mathrm{L}^{-1} \mathrm{em}$ frutos com $15 \mathrm{~mm}$ a $20 \mathrm{~mm}$ de diâmetro; e 9) BA $80 \mathrm{mg} \mathrm{L}^{-1}$ em frutos com $10 \mathrm{~mm}$ a $20 \mathrm{~mm}$ de diâmetro + Promalin ${ }^{\circledR} 0,5 \mathrm{~mL} \mathrm{~L}^{-1}$ (estádio $\mathrm{G}+7$ DAP - dias após a primeira aplicação de Promalin ${ }^{\circledR}$ ).

Experimento 2. Épocas de aplicação de benziladenina (BA) e carbaryl no raleio químico de macieiras 'Fuji Suprema'/M-7

Foram utilizadas macieiras da cultivar Fuji Suprema/M-7, com densidade de plantio de 1.000 plantas $\mathrm{ha}^{-1}$. O delineamento experimental utilizado foi em blocos casualizados, com seis repetições compostas de uma planta. Foram avaliados os seguintes tratamentos: 1) raleio manual com frutos entre 15 $\mathrm{mm}$ a $20 \mathrm{~mm}$ de diâmetro; 2) BA $80 \mathrm{mg} \mathrm{L}^{-1} \mathrm{em}$ frutos com $5 \mathrm{~mm}$ a $8 \mathrm{~mm}$ de diâmetro; 3) BA $80 \mathrm{mg} \mathrm{L}^{-1} \mathrm{em}$ frutos com $10 \mathrm{~mm}$ a $15 \mathrm{~mm}$ de diâmetro; 4) BA 80 $\mathrm{mg} \mathrm{L}^{-1}$ em frutos com $15 \mathrm{~mm}$ a $20 \mathrm{~mm}$ de diâmetro; 5) BA $80 \mathrm{mg} \mathrm{L}^{-1} \mathrm{em}$ frutos com diâmetro superior a $20 \mathrm{~mm}$; 6) BA $80 \mathrm{mg} \mathrm{L}^{-1}+$ carbaryl $1.000 \mathrm{mg} \mathrm{L}^{-1} \mathrm{em}$ frutos com $5 \mathrm{~mm}$ a $8 \mathrm{~mm}$ de diâmetro; 7) BA $80 \mathrm{mg}$ $\mathrm{L}^{-1}+$ carbaryl $1.000 \mathrm{mg} \mathrm{L}^{-1}$ em frutos com $10 \mathrm{~mm}$ a $15 \mathrm{~mm}$ de diâmetro; 8) BA $80 \mathrm{mg} \mathrm{L}^{-1}+$ carbaryl 1.000 $\mathrm{mg} \mathrm{L}^{-1} \mathrm{em}$ frutos com $15 \mathrm{~mm}$ a $20 \mathrm{~mm}$ de diâmetro; e 9) BA $80 \mathrm{mg} \mathrm{L}^{-1}+$ carbaryl $1.000 \mathrm{mg} \mathrm{L}^{-1} \mathrm{em}$ frutos com diâmetro superior a $20 \mathrm{~mm}$.

Experimento 3. Avaliação de raleantes químicos em macieiras 'Fuji Suprema'/M-26

Foram utilizadas macieiras da cultivar Fuji Suprema /M-26, com densidade de plantio de 2.500 plantas $\mathrm{ha}^{-1}$. O delineamento experimental utilizado foi em blocos casualizados, com seis repetições. Cada repetição foi composta de uma planta. Os tratamentos testados foram: 1) raleio manual com frutos entre 15 mm a 20 mm de diâmetro; 2) BA $80 \mathrm{mg} \mathrm{L}^{-1}$ entre os estádios fenológicos G-H (final de floração-queda de pétalas); 3) BA $80 \mathrm{mg} \mathrm{L}^{-1}$ em frutos com $5 \mathrm{~mm}$ a $8 \mathrm{~mm}$ de diâmetro; 4) BA $80 \mathrm{mg} \mathrm{L}^{-1}+$ carbaryl $1.000 \mathrm{mg} \mathrm{L}^{-1}$ em frutos com $10 \mathrm{~mm}$ a $15 \mathrm{~mm}$ de diâmetro; 5) BA $80 \mathrm{mg} \mathrm{L}^{-1}+$ carbary $1.000 \mathrm{mg} \mathrm{L}^{-1}$ em frutos com diâmetro superior a $20 \mathrm{~mm}$; 6) BA 80 
mg L ${ }^{-1}+$ Promalin $^{\circledR} 0,5 \mathrm{~mL} \mathrm{~L}^{-1}$ aplicado no estádio $\mathrm{G}+$ Promalin $0,5 \mathrm{~mL} \mathrm{~L}^{1}$ aos 7 e aos 15 dias após a primeira aplicação.

Experimento 4. Avaliação de raleantes químicos em macieiras'Lisgala'/M-26

Foram utilizadas macieiras da cultivar Lisgala/M-26, com densidade de plantio de 2.500 plantas $\mathrm{ha}^{-1}$. O delineamento experimental utilizado foi em blocos casualizados, com seis repetições compostas de uma planta, sendo avaliados os seguintes tratamentos: 1) raleio manual com frutos entre $15 \mathrm{~mm}$ a $20 \mathrm{~mm}$ de diâmetro; 2) BA $40 \mathrm{mg} \mathrm{L}^{-1}$ no estádio F2 (plena floração); 3) BA $40 \mathrm{mg} \mathrm{L}^{-1}$ entre os estádios fenológicos G-H (final de floração-queda de pétalas); 4) $\mathrm{BA} 40 \mathrm{mg} \mathrm{L}^{-1} \mathrm{em}$ frutos com $5 \mathrm{~mm}$ a $8 \mathrm{~mm}$ de diâmetro; 5) BA $40 \mathrm{mg} \mathrm{L}^{-1} \mathrm{em}$ frutos com $10 \mathrm{~mm}$ a $15 \mathrm{~mm}$ de diâmetro; 6) BA $40 \mathrm{mg} \mathrm{L}^{-1}$ em frutos com diâmetro superior a $20 \mathrm{~mm}$ de diâmetro; 7) BA 40 mg L ${ }^{-1}+$ carbaryl $1.000 \mathrm{mg} \mathrm{L}^{-1}$ em frutos com $10 \mathrm{~mm}$ a $15 \mathrm{~mm}$ de diâmetro; 8) BA $40 \mathrm{mg} \mathrm{L}^{-1}+$ carbaryl $1.000 \mathrm{mg} \mathrm{L}^{-1}$ em frutos com diâmetro superior a 20 mm de diâmetro; e 9) BA 40 mg L-1 (frutos com 10 a $15 \mathrm{~mm}$ de diâmetro) + Promalin $^{\circledR} 0,5 \mathrm{mLL}-1$ (estádio $\mathrm{G}+7$ dias após a primeira aplicação).

Em todos os experimentos realizados, no tratamento raleio manual, foi adotado o critério mantendo até dois frutos por brindila e mantido um fruto por esporão em todos os experimentos realizados. $\mathrm{O}$ complemento de raleio manual nos tratamentos com raleio químico foi realizado apenas no experimento 1 , devido ao excesso de frutificação evidenciado no pomar.

Como fonte de 6-benziladenia (BA) e carbaryl, foram utilizados nos experimentos os produtos comerciais $\mathrm{MaxCel}^{\circledR}(2 \%$ de ingrediente ativo - i.a.) e Sevin ${ }^{\circledR}$ (48\% i.a.), respectivamente. O Promalin ${ }^{\circledR}$, utilizado em alguns tratamentos, é um fitorregulador composto pelas giberelinas $\mathrm{GA}_{4+7}(1,8 \%)$ e pela citocinina 6-benziladenina $(1,8 \%)$ (VALENT BIOSCIENCES, 2012). A aplicação dos tratamentos foi realizada por meio de aspersão com pulverizador costal motorizado, equipado com ponteira contendo três bicos D-S tipo leque, utilizando volume médio de calda correspondente a $1.000 \mathrm{~L} \mathrm{ha}^{-1}$.

As variáveis avaliadas foram número de frutos raleados manualmente, porcentagem de frutos raleados, número de frutos por planta, produção por planta $(\mathrm{Kg})$ e por área da secção do tronco, massa média dos frutos, frutificação efetiva, firmeza de polpa, sólidos solúveis, índice de iodo-amido, classificação dos frutos por classes de tamanho classe 135 - menor ou igual a 135 frutos por caixa; (classe $150-180-150$ a 180 frutos por caixa; classe $>198-$ maior ou igual a 198 frutos por caixa) e porcentagem de inflorescências de acordo com o número de frutos. Os dados das variáveis número de frutos por planta e número de frutos raleados manualmente foram transformados para $(x+1)^{1 / 2}$. Já os dados da variável classificação dos frutos por classe de tamanho foram transformados para arco-seno $(\mathrm{x} / 100)^{1 / 2}$. Os resultados obtidos foram submetidos à análise de variância, sendo efetuada a comparação de médias pelo teste de Tukey, a 5\% de probabilidade de erro. As análises estatísticas foram realizadas utilizando o programa Winstat, versão 2.0 (MACHADO; CONCEIÇÃO, 2003).

\section{RESULTADOS E DISCUSSÃO}

\section{Experimento 1. Avaliação de ralean- tes químicos em macieiras 'Fuji Suprema'/ Marubakaido/M-9}

A intensidade de repasse do raleio manual em macieiras 'Fuji Suprema', após o raleio químico, foi menor nos tratamentos de BA $120 \mathrm{mg} \mathrm{L}^{-1} \mathrm{em}$ frutos de $5 \mathrm{~mm}$ a $8 \mathrm{~mm}$ e BA $80 \mathrm{mg} \mathrm{L}^{-1}+$ Carbaryl $1.000 \mathrm{mg} \mathrm{L}^{-1} \mathrm{em}$ frutos de $10 \mathrm{~mm}$ a $15 \mathrm{~mm}$, com redução de $71,9 \%$ e $62,4 \%$ em relação ao raleio manual, respectivamente. Nos demais tratamentos de raleio químico, apesar de não apresentarem diferenças significativas, também se observou a tendência de redução na intensidade do repasse manual, ficando entre $36,0 \%$ e $55,6 \%$ (Tabela 1 ).

Resultados similares foram obtidos por Guak et al. (2009), em que os tratamentos com BA reduziram significativamente o tempo de repasse manual, e os melhores resultados foram obtidos com a mistura de BA + carbaryl. De acordo com Byers e Carbough (1991), a combinação de BA com carbaryl tem sido mais efetiva que a aplicação isolada, sendo considerada uma das combinações de substâncias mais efetivas para o raleio químico da macieira.

$\mathrm{O}$ aumento do número de frutos raleados pelo uso de raleantes químicos representa a redução de mão de obra, com consequente redução dos custos de produção. Os tratamentos de BA $120 \mathrm{mg} \mathrm{L}^{-1} \mathrm{em}$ frutos 5 a 8 mm e BA $120 \mathrm{mg} \mathrm{L}^{-1}+$ carbaryl 1.000 $\mathrm{mg} \mathrm{L}^{-1}$ em frutos de 10 a $15 \mathrm{~mm}$ foram os tratamentos com menor necessidade de repasse de raleio manual após o raleio químico. O menor número de frutos por planta, após os tratamentos de raleio, foi verificado nas plantas tratadas com BA $120 \mathrm{mg} \mathrm{L}^{-1} \mathrm{em}$ frutos de 5-8 mm, BA $80 \mathrm{mg} \mathrm{L}^{-1}+$ carbaryl $1.000 \mathrm{mg} \mathrm{L}^{-1}$ e BA $80 \mathrm{mg} \mathrm{L}^{-1}+$ carbaryl $1.000 \mathrm{mg} \mathrm{L}^{-1} \mathrm{em}$ frutos de $10-15 \mathrm{~mm}$, sendo significativamente menor ao observado no raleio manual (Tabela 1).

Os tratamentos com maior concentração de 
BA mostraram maior redução do número de frutos por planta (Tabela 1). De acordo com resultados de Costa et al. (2004), o efeito raleante da BA em macieiras 'Golden Delicious' aumentou linearmente com o aumento das concentrações aplicadas em frutos com 10 a $12 \mathrm{~mm}$ de diâmetro. Contudo, adicionando-se carbaryl ao tratamento com a menor concentração de BA, obtendo-se resultado similar aos tratamentos com concentrações maiores de BA. Isto se deve, provavelmente, à ação mais tardia do carbaryl, interferindo diretamente na disponibilidade de carboidratos, causando, desta forma, a queda dos frutos de menor tamanho (EDGERTON; WILLIAMS, 1981). Embora o mecanismo de ação da BA não seja claro, Yuan e Greene (2000) sugerem que o efeito raleante da BA ocorre pela redução do fluxo de carboidratos para os frutos devido ao aumento da respiração durante a noite. Além disso, Greene et al. (1992) relataram que a aplicação de BA estimulou a produção de etileno em folhas e frutos, potencializando a abscisão dos pequenos frutos.

Nos tratamentos com menores concentrações de BA (T2 e T3), a época de aplicação não influenciou o número de frutos por planta, mas o efeito foi significativo nos tratamentos de maior concentração. A concentração de $120 \mathrm{mg} \mathrm{L}^{-1}$ de BA apresentou redução significativa do número de frutos por planta quando aplicado em frutos de $5 \mathrm{~mm}$ a 8 $\mathrm{mm}$ de diâmetro, mas não em frutos de $10 \mathrm{~mm}$ a 15 $\mathrm{mm}$, quando comparados ao raleio manual. Quando comparado BA $120 \mathrm{mg} \mathrm{L}^{-1}$ no estádio de aplicação de 5 a $8 \mathrm{~mm}$ e 10 a $15 \mathrm{~mm}$, não houve diferença significativa entre ambos, porém a aplicação de BA em frutos de menor tamanho repercutiu no menor número de frutos por planta. Isto pode estar relacionado à maior divisão celular promovida pela aplicação de BA, aumentando a competição por carboidratos dos frutos de maior tamanho em detrimento dos menores (YUAN; GREENE, 2000). Estes resultados vão de encontro aos trabalhos de Stopar e Lokar (2003), Petri et al. (2006) e Ambrožič Turk e Stopar (2010), que mostraram a melhor resposta ao raleio químico com BA em frutos com diâmetro em torno de $10 \mathrm{~mm}$.

Já segundo Greene e Autio (1989), a resposta máxima de raleio foi obtida com aplicações de BA em frutos de $10 \mathrm{~mm}$ a $14 \mathrm{~mm}$ de diâmetro em macieiras 'McIntosh'. Tal divergência de resultados pode ser devida às diferentes cultivares utilizadas e às condições climáticas locais. Quando utilizada a mistura de BA $80 \mathrm{mg} \mathrm{L}^{-1}$ + carbaryl em frutos de 10 a $15 \mathrm{~mm}$ ocorreu redução do número de frutos em comparação à mesma concentração de $\mathrm{BA}$, no mesmo estádio de aplicação (Tabela 1).

A produção por planta teve comportamento similar ao número de frutos por planta. As aplicações de BA $120 \mathrm{mg} \mathrm{L}^{-1}$ em frutos de 5-8 mm, BA $80 \mathrm{mg}$ $\mathrm{L}^{-1}+$ carbaryl $1.000 \mathrm{mg} \mathrm{L}^{-1} \mathrm{em}$ frutos de 10 a $15 \mathrm{~mm}$ e BA $120 \mathrm{mg} \mathrm{L}^{-1}+$ Carbaryl $1.000 \mathrm{mg} \mathrm{L}^{-1} \mathrm{em}$ frutos de 10 a $15 \mathrm{~mm}$ proporcionaram menor produção de frutos por planta em relação ao raleio manual (Tabela 2). Esta redução da produção por planta não afetou a produtividade por unidade de área, que se manteve acima de 50 toneladas ha ${ }^{-1}$.

A utilização da mistura de tanque de BA+carbaryl proporciona produção de frutos equivalente à aplicação de maiores concentração de $\mathrm{BA}$ isoladamente, mesmo quando aplicado em frutos de maior diâmetro (Tabela 2). Quanto à produção por área da secção do tronco, as menores produções foram obtidas nos mesmos tratamentos que apresentaram menor produção por planta, porém não diferiram significativamente do raleio manual e dos demais tratamentos (Tabela 2).

$\mathrm{O}$ raleio de frutos pode determinar redução da produtividade, quando considerado apenas um único ciclo, porém o aumento da massa média dos frutos remanescentes resultará em frutos de maior valor comercial, compensando parcialmente a perda de rendimento determinada pelo raleio (STOVER et al., 2004). Assim, a prática do raleio permite ajustar a carga de frutos por planta, proporcionando produções mais estáveis ao longo dos anos devido à melhoria do desenvolvimento vegetativo.

A massa média dos frutos foi maior quando aplicado BA $80 \mathrm{mg} \mathrm{L}^{-1}+$ carbaryl $1.000 \mathrm{mg} \mathrm{L}^{-1}$, em frutos entre 10 a $15 \mathrm{~mm}$, o qual diferiu significativamente do raleio manual, porém não diferiu dos demais tratamentos (Tabela 2). O aumento da massa média dos frutos pelo uso do BA pode estar relacionado à ação na divisão celular, pois o número e o tamanho de células são os determinantes do tamanho final dos frutos (BERTIN et al., 2002; HAMADA et al., 2008).

Um dos principais objetivos do raleio químico é o aumento do tamanho dos frutos e a obtenção de frutos nas classes de maior calibre, sendo o mesmo obtido, de maneira geral, nos tratamentos de BA 80 $\mathrm{mg} \mathrm{L}^{-1}$ aplicada em frutos com 5 a $8 \mathrm{~mm}$, quando aplicado nesta mesma concentração em mistura com carbaryl $1.000 \mathrm{mg} \mathrm{L}^{-1}$ em frutos de 10 a $15 \mathrm{~mm}$, e com a aplicação de BA $120 \mathrm{mg} \mathrm{L}^{-1}$ e BA $120 \mathrm{mg} \mathrm{L}^{-1}$ + Carbaryl $1.000 \mathrm{mg} \mathrm{L}^{-1}$ aplicados entre 5 e $20 \mathrm{~mm}$ (Figura 3).

A mistura de tanque de BA $80 \mathrm{mg} \mathrm{L}^{-1}+$ Carbaryl $1.000 \mathrm{mg} \mathrm{L}^{-1}$, em frutos de 10 a $15 \mathrm{~mm}$, foi o tratamento em que se observou o aumento significativo do número de frutos nas classes de tamanho $<135$ e a redução também significativa na classe $>198$ (Figura 
1). O raleio químico proporcionou a qualificação no calibre dos frutos, em comparação ao raleio manual, possivelmente devido à ação seletiva dos raleantes químicos sobre os frutos com menor potencial de desenvolvimento. Já a realização do raleio manual está sujeita à escolha subjetiva do executor, podendo neste caso ocorrer retirada ou permanência de frutos indevidos.

A resistência da polpa e o índice de iodo amido não foram influenciados pelos tratamentos de raleio químico, visto que não foram verificadas diferenças significativas entre tratamentos (Tabela 3). A aplicação de BA $80 \mathrm{mg} \mathrm{L}^{-1}$ e BA $120 \mathrm{mg} \mathrm{L}^{-1}$, em frutos de 10-15 mm de diâmetro, isoladamente ou em combinação ao carbaryl a $1.000 \mathrm{mg} \mathrm{L}^{-1}$, aumentou significativamente o conteúdo de sólidos solúveis em relação ao raleio manual (Tabela 3 ).

Experimento 2. Épocas de aplicação de benziladenina (BA) e carbaryl no raleio químico de macieiras 'Fuji Suprema'/M-7

A frutificação efetiva de macieiras 'Fuji Suprema' não apresentou diferença significativa em relação ao raleio manual, à exceção do tratamento de BA $80 \mathrm{mg} \mathrm{L}^{-1}+$ carbaryl $1.000 \mathrm{mg} \mathrm{L}^{-1}$ em frutos com diâmetro de 5 a $8 \mathrm{~mm}$ (Tabela 4). Esta resposta evidencia que BA ou BA+carbaryl apresentam ação raleante de pós-floração, visto que a frutificação efetiva do raleio manual, após sua realização, dentro do critério de manter dois frutos por brindila e um fruto por esporão, mostrou-se similar aos tratamentos de raleantes químicos, em que não foi realizado repasse manual.

Quando efetuada a aplicação de raleantes químicos em frutos de maior tamanho, houve a tendência de redução da frutificação efetiva, bem como a aplicação de BA repercutiu em menores índices de frutificação efetiva em comparação à mistura de tanque de BA+carbaryl (Tabela 4). Esta resposta pode ser atribuída à floração desuniforme, pois a aplicação em frutos de maior tamanho proporcionou ação raleante em flores tardias, o mesmo não ocorrendo quando aplicado em frutos menores $(5-8 \mathrm{~mm})$, cujas flores não estavam abertas. O tratamento de BA $80 \mathrm{mg} \mathrm{L}^{-1}+$ carbaryl $1.000 \mathrm{mg} \mathrm{L}^{-1}$, em frutos com diâmetro de 5-8 mm, apresentou frutificação efetiva maior em comparação ao raleio manual, indicando menor eficiência de raleio em relação aos demais raleantes químicos. Segundo Robinson e Lakso (2004), a temperatura é um fator ambiental decisivo na eficiência de diferentes raleantes químicos, já que as aplicações de BA apresentam melhor eficiência quando realizadas à em temperatura de $20^{\circ} \mathrm{C}$. Considerando que a temperatura média na data de aplicação do tratamento BA $80 \mathrm{mg} \mathrm{L}^{-1}+$ carbaryl
$1.000 \mathrm{mg} \mathrm{L}^{-1}$, em frutos de 5 a $8 \mathrm{~mm}$, foi de $12^{\circ} \mathrm{C}$, a menor eficiência deste tratamento pode ser atribuída à temperatura no momento da aplicação.

O número e a produção de frutos por planta, assim como a massa média dos frutos, em macieiras 'Fuji Suprema', não diferiram significativamente entre os diversos tratamentos de raleio avaliados (Tabela 4). Contudo, os tratamentos de BA $80 \mathrm{mg}$ $\mathrm{L}^{-1}$ aplicados em frutos de 5 a $8 \mathrm{~mm}$, isoladamente ou em combinação com carbaryl $1.000 \mathrm{mg} \mathrm{L}^{-1}$, aumentaram significativamente a proporção de frutos de maior calibre $(>110)$, assim como diminuíram a porcentagem de frutos nas classes de menor calibre (Figura 2).

Os resultados obtidos em macieiras 'Fuji Suprema' confirmam que a BA, isoladamente ou associada ao carbaryl, apresenta maior ação raleante quando aplicada em frutos de menor calibre.

Experimento 3. Avaliação de raleantes químicos em macieiras 'Fuji Suprema'/M-26

As diferentes épocas de aplicação de BA não diferiram significativamente do raleio manual, assim como entre tratamentos de BA+carbaryl quanto à frutificação efetiva de macieiras 'Fuji Suprema' (Tabela 5). Quanto ao número de frutos por inflorescência, observa-se maior porcentagem de inflorescências com um fruto, nos tratamentos com raleantes químicos, e menor porcentagem de inflorescências com mais de três frutos, sendo uma resposta desejável no raleio da macieira (Tabela 5 ).

Os diferentes raleantes químicos avaliados não diferiram do raleio manual em relação ao número de frutos por planta, mesmo não tendo sido realizado o repasse de raleio manual após o raleio químico, sendo a mesma resposta evidenciada na produção de frutos por planta (Tabela 6). Isto evidencia que BA, BA + carbaryl e BA + Promalin ${ }^{\circledR}$ tiveram ação raleante efetiva em macieiras 'Fuji Suprema'. À exceção dos tratamentos de BA $80 \mathrm{mg} \mathrm{L}^{-1}$ em frutos de 5-8 mm e BA $80 \mathrm{mg} \mathrm{L}^{-1}+$ carbaryl $1.000 \mathrm{mg} \mathrm{L}^{-1}$, em frutos com diâmetro superior a $20 \mathrm{~mm}$, os demais tratamentos apresentaram massa média dos frutos superior ao observado no tratamento com raleio manual.

O tratamento de BA $80 \mathrm{mg} \mathrm{L}^{-1}+$ carbaryl 1.000 $\mathrm{mg} \mathrm{L}^{-1}$, em frutos de 10 a $15 \mathrm{~mm}$ de diâmetro, proporcionou aumento de $14,7 \%$ em relação ao raleio manual (Tabela 6). O aumento da massa média dos frutos contribuiu para o aumento da porcentagem de frutos na classe $>110$, que são os frutos de maior valor comercial (Figura 3). A aplicação de BA $80 \mathrm{mg} \mathrm{L}^{-1}$ no estádio G-H, BA $80 \mathrm{mg} \mathrm{L}^{-1}+$ Carbaryl $1.000 \mathrm{mg} \mathrm{L}^{-1}$, em frutos de 10 a 15 mm de diâmetro, e BA $80 \mathrm{mg} \mathrm{L}^{-1}+$ Promalin $\mathbb{R}$ $0,5 \mathrm{~mL} \mathrm{~L}^{-1}$ aplicado no estádio $\mathrm{G}+$ Promalin $0,5 \mathrm{~mL}$ $\mathrm{L}^{1}$, aos 7 e aos 15 dias após a primeira aplicação, teve 
porcentagem de frutos de $13,9 \%$ a $14,7 \%$ superior ao raleio manual na classe $>110$. Nas demais classes de tamanho dos frutos, não foram verificadas diferenças significativas entre tratamentos (Figura 3).

Experimento 4. Avaliação de raleantes químicos em macieiras 'Lisgala'/M-26

A frutificação efetiva em macieiras 'Lisgala' apresentou grande variabilidade e, em consequência, não houve diferença significativa entre tratamentos, embora o tratamento de raleio manual tenha apresentado a maior frutificação efetiva, com 46,4\%, e o tratamento de BA $40 \mathrm{mg} \mathrm{L}^{-1}$, em frutos de 5 a $8 \mathrm{~mm}$, tenha somente 18,2\% (Tabela 7.). Estes resultados não evidenciam efeito da época de aplicação de BA e da adição de carbaryl ou Promalin ${ }^{\circledR}$ na redução da frutificação efetiva de macieiras 'Lisgala' (Tabela 7). Nos tratamentos de BA, BA + carbaryl e BA + Promalin $^{\circledR}$, observa-se a tendência de aumento da porcentagem de inflorescências com um fruto em relação ao raleio manual, além de redução de inflorescências com três frutos (Tabela 7).

$\mathrm{O}$ tratamento de BA $40 \mathrm{mg} \mathrm{L}^{-1}$, em frutos $10 \mathrm{a}$ $15 \mathrm{~mm}$, e Promalin ${ }^{\circledR} 0,5 \mathrm{~mL} \mathrm{~L}^{-1}$ no estádio $\mathrm{G}$ e 7 dias após, reduziu significativamente o número de frutos por planta em relação ao raleio manual, e BA $40 \mathrm{mg}$ $\mathrm{L}^{-1}$ no estádio $\mathrm{F} 2$ e BA $40 \mathrm{mg} \mathrm{L}^{-1}$, em frutos de 5 a 8 mm de diâmetro (Tabela 8). Os demais tratamentos não apresentaram diferenças significativas entre si quanto ao número de frutos por planta.
A produção de frutos por planta nos tratamentos BA $40 \mathrm{mg} \mathrm{L}^{-1}$, em frutos de $10 \mathrm{~mm}$ a $15 \mathrm{~mm}$ e BA $40 \mathrm{mg} \mathrm{L}^{-1}$ em frutos de 10 a $15 \mathrm{~mm}+$ Promalin $^{\circledR}$ $0,5 \mathrm{mg} \mathrm{L}^{-1}$ estádio $\mathrm{G}$ e 7 dias após, foi menor do que o observado no raleio manual (Tabela 8). A menor produção de frutos em tais tratamentos não apresenta relação direta com a frutificação efetiva, pois os mais baixos índices de frutificação foram evidenciados nos tratamentos de BA $40 \mathrm{mg} \mathrm{L}^{-1}$ aplicada em frutos de 5 a $8 \mathrm{~mm}$ e em frutos maiores que $20 \mathrm{~mm}$ de diâmetro.

Quanto à massa média dos frutos, não foram verificadas diferenças significativas entre tratamentos (Tabela 8). Com a menor produção de frutos por planta, existe a tendência de aumento da massa média dos frutos. No entanto, os tratamentos com menor produção de frutos por planta não apresentaram a maior massa média de frutos, podendo esta resposta ser associada ao tipo de gema em que houve o predomínio na frutificação. Nachtigall (2000) e Madail et al. (2010), estudando as estruturas de frutificação das cultivares Gala e Fuji, observaram que frutos oriundos de gemas terminais em brindilas têm maior potencial de desenvolvimento, com maior massa final, quando comparado a frutos produzidos em gemas axilares e em esporões. Possivelmente, nos tratamentos que resultaram na menor produção de frutos por planta e menor massa média dos frutos, os frutos remanescentes do raleio tenham sido predominantemente localizados em esporões e gemas axilares.

TABELA 1- Número de frutos por planta, número de frutos raleados por planta e porcentagem de frutos raleados em macieiras 'Fuji Suprema', enxertadas sobre o porta-enxerto Marubakaido com interenxerto de M-9, em função de diferentes tratamentos de raleio. Fraiburgo-SC.

\begin{tabular}{|c|c|c|c|}
\hline Tratamentos & $\begin{array}{l}\text { Número de frutos } \\
\text { por planta }\end{array}$ & $\begin{array}{l}\text { Número de frutos } \\
\text { raleados por planta }\end{array}$ & $\begin{array}{c}\text { Frutos } \\
\text { raleados } \\
(\%)\end{array}$ \\
\hline 1) Raleio manual (frutos de $15 \mathrm{~mm}$ a $20 \mathrm{~mm}$ de diâmetro) & $320,7 \mathrm{a}$ & $96,2 \mathrm{a}$ & $41,3 \mathrm{a}$ \\
\hline 2) $\mathrm{BA} 80 \mathrm{mg} \mathrm{L}^{-1}$ (frutos de $5 \mathrm{~mm}$ a $8 \mathrm{~mm}$ de diâmetro) & $210,5 \mathrm{ab}$ & $50,0 \mathrm{ab}$ & $21,5 \mathrm{ab}$ \\
\hline 3) $\mathrm{BA} 80 \mathrm{mg} \mathrm{L}^{-1}$ (frutos de $10 \mathrm{~mm}$ a $15 \mathrm{~mm}$ de diâmetro) & $214,5 \mathrm{ab}$ & $61,5 \mathrm{ab}$ & $26,4 \mathrm{ab}$ \\
\hline 4) $\mathrm{BA} 120 \mathrm{mg} \mathrm{L}^{-1}$ (frutos de $5 \mathrm{~mm}$ a $8 \mathrm{~mm}$ de diâmetro) & $164,0 \mathrm{~b}$ & $27,0 \mathrm{~b}$ & $11,6 b$ \\
\hline 5) BA $120 \mathrm{mg} \mathrm{L}^{-1}$ (frutos de $10 \mathrm{~mm}$ a $15 \mathrm{~mm}$ de diâmetro) & $247,3 \mathrm{ab}$ & $42,7 \mathrm{ab}$ & $18,3 b$ \\
\hline $\begin{array}{l}\text { 6) BA } 80 \mathrm{mg} \mathrm{L}^{-1}+\text { Carbaryl } 1.000 \mathrm{mg} \mathrm{L}^{-1} \\
\text { (frutos com } 10 \mathrm{~mm} \text { a } 15 \mathrm{~mm} \text { de diâmetro) }\end{array}$ & $153,3 b$ & $36,2 b$ & $15,5 b$ \\
\hline $\begin{array}{l}\text { 7) } \mathrm{BA} 120 \mathrm{mg} \mathrm{L}^{-1}+\text { Carbaryl } 1.000 \mathrm{mg} \mathrm{L}^{-1} \\
\text { (frutos com } 10 \mathrm{~mm} \text { a } 15 \mathrm{~mm} \text { de diâmetro) }\end{array}$ & $172,0 \mathrm{~b}$ & $46,5 \mathrm{ab}$ & $20,0 \mathrm{ab}$ \\
\hline $\begin{array}{l}\text { 8) BA } 120 \mathrm{mg} \mathrm{L}^{-1}+\text { Carbaryl } 1.000 \mathrm{mg} \mathrm{L}^{-1} \\
\text { (frutos com } 15 \mathrm{~mm} \text { a } 20 \mathrm{~mm} \text { de diâmetro) }\end{array}$ & $264,7 \mathrm{ab}$ & $59,7 \mathrm{ab}$ & $25,6 \mathrm{ab}$ \\
\hline $\begin{array}{l}\left.\text { 9) BA } 80 \mathrm{mg} \mathrm{L}^{-1} \text { (frutos com } 10-15 \mathrm{~mm}\right)+ \text { Promalin }^{\circledR} \\
0,5 \mathrm{~mL} \mathrm{~L}^{-1} \text { (estádio G + } 7 \text { DAP) }\end{array}$ & $220,2 \mathrm{ab}$ & $46,0 \mathrm{ab}$ & $19,7 \mathrm{ab}$ \\
\hline Média geral & 218,6 & 51,8 & 22,2 \\
\hline CV $(\%)$ & 16,8 & 21,2 & 29,4 \\
\hline
\end{tabular}

Médias seguidas de mesma letra nas colunas não diferem entre si, pelo teste de Tukey, a 5\% de probabilidade. DAP - dias após a primeira aplicação de $\operatorname{Promalin}^{\circledR}$. 
TABELA 2- Produção de frutos por planta e por área da secção do tronco e massa média dos frutos em macieiras 'Fuji Suprema', enxertadas sobre o porta-enxerto Marubakaido com interenxerto de M-9, em distintos tratamentos de raleio. Fraiburgo-SC.

Tratamentos
Produção de Produção/área Massa frutos por planta secção do tronco média dos frutos

1) Raleio manual (frutos com $15 \mathrm{~mm}$ a $20 \mathrm{~mm}$ de diâmetro)

kg planta $^{-1}$

$\mathrm{g} \mathrm{cm}^{-2}$ g fruto $^{-1}$

2) BA $80 \mathrm{mg} \mathrm{L}^{-1}$ (frutos com $5 \mathrm{~mm}$ a $8 \mathrm{~mm}$ de diâmetro)

$47,1 \mathrm{a}$

$1148,9 \mathrm{ab} \quad 148,1 \mathrm{~b}$

3) BA $80 \mathrm{mg} \mathrm{L}^{-1}$ (frutos com $10 \mathrm{~mm}$ a $15 \mathrm{~mm}$ de diâmetro)

$36,5 \mathrm{ab}$

$918,7 \mathrm{ab} \quad 174,0 \mathrm{ab}$

4) BA $120 \mathrm{mg} \mathrm{L}^{-1}$ (frutos com $5 \mathrm{~mm}$ a $8 \mathrm{~mm}$ de diâmetro)

$34,0 \mathrm{ab}$

$1139,7 \mathrm{ab}$

$171,1 \mathrm{ab}$

5) $\mathrm{BA} 120 \mathrm{mg} \mathrm{L}^{-1}$ (frutos com $10 \mathrm{~mm}$ a $15 \mathrm{~mm}$ de diâmetro)

$28,9 \mathrm{~b}$

$828,6 \mathrm{ab}$

$176,9 \mathrm{ab}$

6) BA $80 \mathrm{mg} \mathrm{L}^{-1}+$ Carbaryl $1.000 \mathrm{mg} \mathrm{L}^{-1}$

(frutos com $10 \mathrm{~mm}$ a $15 \mathrm{~mm}$ de diâmetro)

$38,8 \mathrm{ab}$

1216,8 a

$158,3 \mathrm{ab}$

7) BA $120 \mathrm{mg} \mathrm{L}^{-1}+$ Carbaryl $1.000 \mathrm{mg} \mathrm{L}^{-1}$

(frutos com $10 \mathrm{~mm}$ a $15 \mathrm{~mm}$ de diâmetro)

$28,8 \mathrm{~b} \quad 772,2 \mathrm{~b} \quad 192,6 \mathrm{a}$

8) BA $120 \mathrm{mg} \mathrm{L}^{-1}+$ Carbaryl $1.000 \mathrm{mg} \mathrm{L}^{-1}$

(frutos com $15 \mathrm{~mm}$ a $20 \mathrm{~mm}$ de diâmetro)

$29,3 b$

$910,0 \mathrm{ab}$

$171,6 a b$

$41,9 \mathrm{ab}$

$1160,0 \mathrm{ab}$

$157,6 a b$

9) BA $80 \mathrm{mg} \mathrm{L}-1$ (frutos com $10-15 \mathrm{~mm}$ ) + Promalin $^{\circledR} 0,5 \mathrm{~mL}$ $\mathrm{L}^{-1}$ (estádio G + 7 DAP)

\begin{tabular}{lccc} 
Média geral & 35,9 & 1000,3 & 169,2 \\
CV $(\%)$ & 28,4 & 24,1 & 12,0 \\
\hline
\end{tabular}

Médias seguidas de mesma letra nas colunas não diferem entre si, pelo teste de Tukey, a 5\% de probabilidade. DAP - dias após a primeira aplicação de $\operatorname{Promalin}^{\circledR}$.

TABELA 3 - Efeito de diferentes tratamentos de raleio na resistência da polpa, índice de iodo-amido e sólidos solúveis em maçãs 'Fuji Suprema', enxertadas sobre o porta-enxerto Marubakaido com interenxerto de M-9 Fraiburgo-SC.

Tratamentos

1) Raleio manual (frutos com $15 \mathrm{~mm}$ a $20 \mathrm{~mm}$ de diâmetro)

2) BA $80 \mathrm{mg} \mathrm{L}^{-1}$ (frutos com $5 \mathrm{~mm}$ a $8 \mathrm{~mm}$ de diâmetro)

Resistência Índice Sólidos

da polpa (lb) Iodo-amido solúveis

3) BA $80 \mathrm{mg} \mathrm{L}^{-1}$ (frutos com $10 \mathrm{~mm}$ a $15 \mathrm{~mm}$ de diâmetro)

4) BA $120 \mathrm{mg} \mathrm{L}^{-1}$ (frutos com $5 \mathrm{~mm}$ a $8 \mathrm{~mm}$ de diâmetro)

5) $\mathrm{BA} 120 \mathrm{mg} \mathrm{L}^{-1}$ (frutos com $10 \mathrm{~mm}$ a $15 \mathrm{~mm}$ de diâmetro)

6) BA $80 \mathrm{mg} \mathrm{L}^{-1}+$ Carbaryl $1.000 \mathrm{mg} \mathrm{L}^{-1}$

(frutos com $10 \mathrm{~mm}$ a $15 \mathrm{~mm}$ de diâmetro)

$\mathrm{lb} \mathrm{cm}^{-2} \quad$ Escala 1-9 $\%$

$14,6 \mathrm{~ns} \quad 6,5 \mathrm{~ns} \quad 13,5 \mathrm{c}$

7) BA $120 \mathrm{mg} \mathrm{L}^{-1}+$ Carbaryl $1.000 \mathrm{mg} \mathrm{L}^{-1}$

(frutos com $10 \mathrm{~mm}$ a $15 \mathrm{~mm}$ de diâmetro)

15,2

7,0

$13,7 \mathrm{bc}$

15,1

6,0

$14,2 \mathrm{ab}$

15,6

6,4

$13,9 \mathrm{bc}$

15,6

6,2

$14,3 \mathrm{ab}$

15,9

6,0

$14,2 \mathrm{ab}$

8) BA $120 \mathrm{mg} \mathrm{L}^{-1}+$ Carbaryl $1.000 \mathrm{mg} \mathrm{L}^{-1}$

(frutos com $15 \mathrm{~mm}$ a $20 \mathrm{~mm}$ de diâmetro)

$15,7 \quad 5,6 \quad 14,6 \mathrm{a}$

$15,3 \quad 6,2 \quad 14,0 \mathrm{abc}$

9) BA 80 mg L-1 (frutos com $10-15 \mathrm{~mm}$ ) + Promalin $^{\circledR} 0,5 \mathrm{~mL} \mathrm{~L}^{-1}$

(estádio G + 7 DAP)

Média geral

15,6

6,0

$13,9 \mathrm{bc}$

CV (\%)

15,4

6,2

14,0

4,2

11,6

2,6

Médias seguidas de mesma letra nas colunas não diferem entre si, pelo teste de Tukey, a 5\% de probabilidade. DAP - dias após a primeira aplicação de Promalin ${ }^{\circledR}$ 
TABELA 4- Frutificação efetiva, número de frutos por planta, produção de frutos por planta e massa média dos frutos em macieiras 'Fuji Suprema', enxertadas sobre o porta-enxerto M-7, em função de diferentes tratamentos de raleio. Caçador-SC.

\begin{tabular}{|c|c|c|c|c|}
\hline Tratamentos & $\begin{array}{c}\begin{array}{c}\text { Frutificação } \\
\text { efetiva }\end{array} \\
\%\end{array}$ & $\begin{array}{c}\text { Número } \\
\text { de frutos por } \\
\text { planta } \\
\text { frutos planta }^{-1}\end{array}$ & $\begin{array}{l}\text { Produção } \\
\text { de frutos } \\
\text { por planta } \\
\text { kg planta }^{-1}\end{array}$ & $\begin{array}{l}\text { Massa } \\
\text { média } \\
\text { dos frutos } \\
\mathrm{g}_{\text {fruto }}{ }^{-1}\end{array}$ \\
\hline $\begin{array}{l}\text { 1) Raleio manual } \\
\text { (frutos com } 15 \mathrm{~mm} \text { a } 20 \mathrm{~mm} \text { de diâmetro) }\end{array}$ & $40,7 b c$ & $142,5 \mathrm{~ns}$ & $21,1 \mathrm{~ns}$ & $148,9 \mathrm{~ns}$ \\
\hline $\begin{array}{l}\text { 2) BA } 80 \mathrm{mg} \mathrm{L}^{-1} \\
\text { (frutos com } 5 \mathrm{~mm} \text { a } 8 \mathrm{~mm} \text { de diâmetro) }\end{array}$ & $48,5 \mathrm{abc}$ & 126,5 & 20,0 & 157,8 \\
\hline $\begin{array}{l}\text { 3) BA } 80 \mathrm{mg} \mathrm{L}^{-1} \\
\text { (frutos com } 10 \mathrm{~mm} \text { a } 15 \mathrm{~mm} \text { de diâmetro) }\end{array}$ & $41,2 \mathrm{bc}$ & 149,5 & 21,8 & 144,5 \\
\hline $\begin{array}{l}\text { 4) BA } 80 \mathrm{mg} \mathrm{L}^{-1} \\
\text { (em frutos com } 15 \mathrm{~mm} \text { a } 20 \mathrm{~mm} \text { de diâmetro) }\end{array}$ & $33,9 b c$ & 144,7 & 21,9 & 151,8 \\
\hline $\begin{array}{l}\text { 5) BA } 80 \mathrm{mg} \mathrm{L}^{-1} \\
\text { (em frutos com diâmetro superior a } 20 \mathrm{~mm} \text { ) }\end{array}$ & $34,5 b c$ & 139,8 & 21,1 & 150,4 \\
\hline $\begin{array}{l}\text { 6) BA } 80 \mathrm{mg} \mathrm{L}^{-1}+\text { carbaryl } 1.000 \mathrm{mg} \mathrm{L}^{-1} \\
\text { (em frutos com } 5 \mathrm{~mm} \text { a } 8 \mathrm{~mm} \text { de diâmetro) }\end{array}$ & $61,5 \mathrm{a}$ & 106,2 & 17,0 & 161,5 \\
\hline $\begin{array}{l}\text { 7) } \mathrm{BA} 80 \mathrm{mg} \mathrm{L}^{-1}+\text { carbaryl } 1.000 \mathrm{mg} \mathrm{L}^{-1} \\
\text { (em frutos com } 10 \mathrm{~mm} \text { a } 15 \mathrm{~mm} \text { de diâmetro) }\end{array}$ & $47,0 \mathrm{abc}$ & 144,5 & 21,6 & 149,6 \\
\hline $\begin{array}{l}\text { 8) BA } 80 \mathrm{mg} \mathrm{L}^{-1}+\text { carbaryl } 1.000 \mathrm{mg} \mathrm{L}^{-1} \\
\text { (em frutos com } 15 \mathrm{~mm} \text { a } 20 \mathrm{~mm} \text { de diâmetro) }\end{array}$ & $53,2 \mathrm{ab}$ & 118,7 & 17,8 & 149,6 \\
\hline $\begin{array}{l}\text { 9) BA } 80 \mathrm{mg} \mathrm{L}^{-1}+\text { carbaryl } 1.000 \mathrm{mg} \mathrm{L}^{-1} \\
\text { (em frutos com diâmetro superior a } 20 \mathrm{~mm} \text {.) }\end{array}$ & $41,3 b c$ & 129,0 & 19,4 & 151,6 \\
\hline Média geral & 44,7 & 133,5 & 20,2 & 151,8 \\
\hline CV (\%) & 29,4 & 26,7 & 26,9 & 6,3 \\
\hline
\end{tabular}

Médias seguidas de mesma letra nas colunas não diferem entre si, pelo teste de Tukey, a $5 \%$ de probabilidade. ns - não significativo $(\mathrm{p}<0,05)$.

TABELA 5 - Frutificação efetiva e porcentagem de inflorescência de acordo com o número de frutos por inflorescência, em macieiras 'Fuji Suprema', enxertadas sobre o porta-enxerto M-26, em distintos tratamentos de raleio. Caçador-SC.

\begin{tabular}{|c|c|c|c|c|c|}
\hline \multirow{2}{*}{ Tratamentos } & \multirow{2}{*}{$\begin{array}{c}\text { Frutificação } \\
\text { efetiva }\end{array}$} & \multicolumn{4}{|c|}{ Inflorescências com } \\
\hline & & 1 fruto & $\begin{array}{l}2 \text { frutos } \\
\%\end{array}$ & 3 frutos & $>3$ frutos \\
\hline $\begin{array}{l}\text { 1) Raleio manual } \\
\text { (frutos com } 15 \mathrm{~mm} \text { a } 20 \mathrm{~mm} \text { de diâmetro) }\end{array}$ & $83,9 \mathrm{~ns}$ & $33,0 \mathrm{a}$ & $35,0 \mathrm{~ns}$ & $19,7 \mathrm{~ns}$ & $12,3 \mathrm{ab}$ \\
\hline 2) BA $80 \mathrm{mg} \mathrm{L}^{-1}$ (estádio G-H) & 115,3 & $37,0 \mathrm{ab}$ & 32,0 & 16,3 & $14,7 \mathrm{a}$ \\
\hline 3) BA $80 \mathrm{mg} \mathrm{L}^{-1}$ (frutos com $5 \mathrm{~mm}$ a $8 \mathrm{~mm}$ de diâmetro) & 53,3 & $41,3 \mathrm{ab}$ & 33,1 & 18,9 & $6,6 \mathrm{~b}$ \\
\hline $\begin{array}{l}\text { 4) } \mathrm{BA} 80 \mathrm{mg} \mathrm{L}^{-1}+\text { carbaryl } 1.000 \mathrm{mg} \mathrm{L}^{-1} \\
\text { (frutos com } 10 \mathrm{~mm} \text { a } 15 \mathrm{~mm} \text { de diâmetro) }\end{array}$ & 66,2 & $43,7 \mathrm{ab}$ & 34,0 & 15,5 & $6,7 \mathrm{ab}$ \\
\hline $\begin{array}{l}\text { 5) BA } 80 \mathrm{mg} \mathrm{L}^{-1}+\text { carbaryl } 1.000 \mathrm{mg} \mathrm{L}^{-1} \\
\text { (frutos }>20 \mathrm{~mm} \text { de diâmetro) }\end{array}$ & 62,1 & $49,1 \mathrm{a}$ & 30,8 & 13,8 & $6,3 b$ \\
\hline $\begin{array}{l}\text { 6) BA } 80 \mathrm{mg} \mathrm{L}^{-1}+\text { Promalin } 0,5 \mathrm{~mL} \mathrm{~L}^{-1} \\
\text { (Estádio } \mathrm{G}+7 \mathrm{DAP}+15 \mathrm{DAP})\end{array}$ & 71,1 & $35,0 \mathrm{ab}$ & 34,8 & 20,8 & $9,4 \mathrm{ab}$ \\
\hline Média geral & 75,3 & 39,9 & 33,3 & 17,5 & 9,3 \\
\hline CV (\%) & 29,6 & 14,8 & 10,3 & 18,6 & 31,6 \\
\hline
\end{tabular}

Médias seguidas de mesma letra nas colunas não diferem entre si, pelo teste de Tukey, a 5\% de probabilidade. DAP - dias após a primeira aplicação de Promalin ${ }^{\circledR}$. 
TABELA 6 - Número de frutos por planta, produção de frutos por planta e massa média dos frutos em macieiras 'Fuji Suprema', enxertadas sobre o porta-enxerto M-26, em distintos tratamentos de raleio. Caçador-SC, 2010.

\begin{tabular}{|c|c|c|c|}
\hline Tratamentos & $\begin{array}{l}\text { Número de frutos } \\
\text { por planta } \\
\text { frutos planta }^{-1} \\
\end{array}$ & $\begin{array}{c}\text { Produção de frutos } \\
\text { por planta } \\
\text { kg planta }^{-1}\end{array}$ & $\begin{array}{c}\text { Massa } \\
\text { média dos frutos } \\
\mathrm{g} \text { fruto } \\
\end{array}$ \\
\hline $\begin{array}{l}\text { 1) Raleio manual } \\
\text { (frutos com } 15 \mathrm{~mm} \text { a } 20 \mathrm{~mm} \text { de diâmetro) }\end{array}$ & $102,8 \mathrm{~ns}$ & $13,4 \mathrm{~ns}$ & $132,7 \mathrm{~b}$ \\
\hline 2) BA $80 \mathrm{mg} \mathrm{L}^{-1}$ (estádio G-H) & 74,7 & 11,1 & $149,7 \mathrm{a}$ \\
\hline $\begin{array}{l}\text { 3) BA } 80 \mathrm{mg} \mathrm{L}^{-1} \\
\text { (frutos com } 5 \mathrm{~mm} \text { a } 8 \mathrm{~mm} \text { de diâmetro) }\end{array}$ & 90,3 & 13,0 & $143,8 \mathrm{ab}$ \\
\hline $\begin{array}{l}\text { 4) } \mathrm{BA} 80 \mathrm{mg} \mathrm{L}^{-1}+\text { carbaryl } 1.000 \mathrm{mg} \mathrm{L}^{-1} \\
\text { (frutos com } 10 \mathrm{~mm} \text { a } 15 \mathrm{~mm} \text { de diâmetro) }\end{array}$ & 62,8 & 9,4 & 152,2 a \\
\hline $\begin{array}{l}\text { 5) BA } 80 \mathrm{mg} \mathrm{L}^{-1}+\text { carbaryl } 1.000 \mathrm{mg} \mathrm{L}^{-1} \\
\text { (frutos }>20 \mathrm{~mm} \text { de diâmetro) }\end{array}$ & 74,5 & 10,5 & $142,9 \mathrm{ab}$ \\
\hline $\begin{array}{l}\text { 6) BA } 80 \mathrm{mg} \mathrm{L}^{-1}+\text { Promalin }^{\circledR} 0,5 \mathrm{~L} / \mathrm{ha} \\
\text { (Estádio G +7 DAP+15 DAP) }\end{array}$ & 68,2 & 10,3 & 151,4 a \\
\hline Média geral & 78,9 & 11,3 & 145,5 \\
\hline CV $(\%)$ & 36,1 & 31,6 & 7,0 \\
\hline
\end{tabular}

Médias seguidas de mesma letra nas colunas não diferem entre si, pelo teste de Tukey, a 5\% de probabilidade. DAP - dias após a primeira aplicação de Promalin ${ }^{\circledR}$.

TABELA 7 - Frutificação efetiva e porcentagem de inflorescência de acordo com o número de frutos por inflorescência em macieiras 'Lisgala', enxertadas sobre o porta-enxerto M-26, em distintos tratamentos de raleio. Caçador-SC, 2010.

\begin{tabular}{|c|c|c|c|c|c|}
\hline \multirow[t]{2}{*}{ Tratamentos } & $\begin{array}{l}\text { Frutificação } \\
\text { efetiva }\end{array}$ & \multicolumn{4}{|c|}{ Inflorescências com } \\
\hline & \multicolumn{5}{|c|}{$\%$} \\
\hline 1) Raleio manual (frutos com $15 \mathrm{~mm}$ a $20 \mathrm{~mm}$ de diâmetro) & $46,4 \mathrm{~ns}$ & $52,7 \mathrm{~b}$ & $29,0 \mathrm{ab}$ & $14,3 \mathrm{a}$ & $4,0 \mathrm{~ns}$ \\
\hline 2) BA $40 \mathrm{mg} \mathrm{L}^{-1}$ (Estádio F2) & 45,7 & $59,0 \mathrm{ab}$ & $24,7 \mathrm{ab}$ & $12,3 \mathrm{ab}$ & 4,0 \\
\hline 3) BA $40 \mathrm{mg} \mathrm{L}^{-1}$ (Estádio G-H) & 25,2 & $60,4 \mathrm{ab}$ & $26,2 \mathrm{ab}$ & $8,3 \mathrm{ab}$ & 5,1 \\
\hline 4) $\mathrm{BA} 40 \mathrm{mg} \mathrm{L}^{-1}$ (frutos com $5 \mathrm{~mm}$ a $8 \mathrm{~mm}$ de diâmetro) & 18,2 & $56,0 \mathrm{ab}$ & $29,3 \mathrm{ab}$ & $11,0 \mathrm{ab}$ & 3,7 \\
\hline 5) BA $40 \mathrm{mg} \mathrm{L}^{-1}$ (frutos com 10 a 15 mm de diâmetro) & 35,4 & $56,8 \mathrm{ab}$ & $31,2 \mathrm{a}$ & $7,1 \mathrm{ab}$ & 4,8 \\
\hline 6) BA40 mg L-1 (frutos $>20 \mathrm{~mm}$ de diâmetro) & 19,6 & $61,7 \mathrm{ab}$ & $29,8 \mathrm{ab}$ & $5,1 \mathrm{~b}$ & 3,4 \\
\hline $\begin{array}{l}\text { 7) BA } 40 \mathrm{mg} \mathrm{L}^{-1}+\text { Carbaryl } 1.000 \mathrm{mg} \mathrm{L}^{-1} \\
\text { (frutos com } 10 \mathrm{~mm} \text { a } 15 \mathrm{~mm} \text { de diâmetro) }\end{array}$ & 32,0 & $61,3 \mathrm{ab}$ & $26,6 \mathrm{ab}$ & 7,9 ab & 4,1 \\
\hline $\begin{array}{l}\text { 8) BA } 40 \mathrm{mg} \mathrm{L}^{-1}+\text { Carbaryl } 1.000 \mathrm{mg} \mathrm{L}^{-1} \\
\text { (frutos }>20 \mathrm{~mm} \text { de diâmetro) }\end{array}$ & 28,0 & $57,2 \mathrm{ab}$ & $27,8 \mathrm{ab}$ & $10,8 \mathrm{ab}$ & 4,1 \\
\hline $\begin{array}{l}\text { 9) BA } 40 \mathrm{mg} \mathrm{L}^{-1} \text { (frutos com } 10 \text { a } 15 \mathrm{~mm} \text { de diâmetro) + } \\
\left.\text { Promalin }{ }^{\circledR} 0,5 \mathrm{~mL} \mathrm{~L}^{-1} \text { (estádio } \mathrm{G}+7 \mathrm{DAP}\right)\end{array}$ & 32,2 & $72,2 \mathrm{a}$ & $20,0 \mathrm{~b}$ & $5,7 \mathrm{~b}$ & 2,1 \\
\hline Média geral & 31,4 & 59,7 & 27,2 & 9,2 & 3,9 \\
\hline CV $(\%)$ & 35,4 & 7,6 & 11,5 & 29,9 & 42,0 \\
\hline
\end{tabular}

Médias seguidas de mesma letra nas colunas não diferem entre si, pelo teste de Tukey, a $5 \%$ de probabilidade. ns - não significativo $(\mathrm{p}<0,05)$. 
TABELA 8 - Número de frutos por planta, massa fresca dos frutos e massa fresca média dos frutos de macieiras 'Lisgala', enxertadas sobre o porta-enxerto M-26, em função dos tratamentos de raleio. Caçador-SC, 2010.

\begin{tabular}{|c|c|c|c|}
\hline Tratamentos & $\begin{array}{l}\text { Número de } \\
\text { frutos por } \\
\text { planta }\end{array}$ & $\begin{array}{l}\text { Produção de } \\
\text { frutos por planta }\end{array}$ & $\begin{array}{l}\text { Massa } \\
\text { média dos } \\
\text { frutos }\end{array}$ \\
\hline & frutos planta ${ }^{-1}$ & $\mathrm{~kg}_{\mathrm{planta}}{ }^{-1}$ & $\mathrm{~g}_{\text {fruto }}^{-1}$ \\
\hline 1) Raleio manual (frutos com 15 mm a 20 mm de diâmetro) & $134,0 \mathrm{a}$ & $14,6 \mathrm{ab}$ & $108,0 \mathrm{~ns}$ \\
\hline 2) BA $40 \mathrm{mg} \mathrm{L}^{-1}$ (Estádio F2) & $125,5 \mathrm{a}$ & $13,8 \mathrm{abc}$ & 111,2 \\
\hline 3) BA $40 \mathrm{mg} \mathrm{L}^{-1}$ (Estádio G-H & $90,2 \mathrm{ab}$ & $10,5 \mathrm{abcd}$ & 116,7 \\
\hline 4) BA $40 \mathrm{mg} \mathrm{L}^{-1}$ (frutos com $5 \mathrm{~mm}$ a $8 \mathrm{~mm}$ de diâmetro & $138,3 \mathrm{a}$ & $16,8 \mathrm{a}$ & 121,1 \\
\hline 5) BA $40 \mathrm{mg} \mathrm{L}^{-1}$ (frutos com 10 a 15 mm de diâmetro) & $81,3 \mathrm{ab}$ & $8,0 \mathrm{~cd}$ & 100,5 \\
\hline 6) BA $40 \mathrm{mg} \mathrm{L}^{-1}$ (frutos com> $20 \mathrm{~mm}$ de diâmetro) & $83,5 \mathrm{ab}$ & $9,2 \mathrm{bcd}$ & 111,7 \\
\hline $\begin{array}{l}\text { 7) BA } 40 \mathrm{mg} \mathrm{L}^{-1}+\text { Carbaryl } 1.000 \mathrm{mg} \mathrm{L}^{-1} \\
\text { (frutos com } 10 \mathrm{~mm} \text { a } 15 \mathrm{~mm} \text { de diâmetro) }\end{array}$ & $98,7 \mathrm{ab}$ & 11,6 abcd & 117,6 \\
\hline $\begin{array}{l}\text { 8) } \mathrm{BA} 40 \mathrm{mg} \mathrm{L}^{-1}+\text { Carbaryl } 1.000 \mathrm{mg} \mathrm{L}^{-1} \\
\text { (frutos com }>20 \mathrm{~mm} \text { de diâmetro) }\end{array}$ & $92,3 \mathrm{ab}$ & 11,0 abcd & 121,2 \\
\hline $\begin{array}{l}\text { 9) BA } 40 \mathrm{mg} \mathrm{L}^{-1} \text { (frutos com } 10 \text { a } 15 \mathrm{~mm} \text { de diâmetro) + } \\
\text { Promalin } 囚 0,5 \mathrm{~mL} \mathrm{~L}^{-1} \text { (estádio } \mathrm{G}+7 \mathrm{DAP} \text { ) }\end{array}$ & $59,7 \mathrm{~b}$ & $6,7 \mathrm{~d}$ & 111,0 \\
\hline Média geral & 100,4 & 11,4 & 113,2 \\
\hline CV $(\%)$ & 37,0 & 37,9 & 10,7 \\
\hline
\end{tabular}

Médias seguidas de mesma letra nas colunas não diferem entre si, pelo teste de Tukey, a $5 \%$ de probabilidade de erro. ns - não significativo pelo teste $\mathrm{F}(\mathrm{p}<0,05)$.

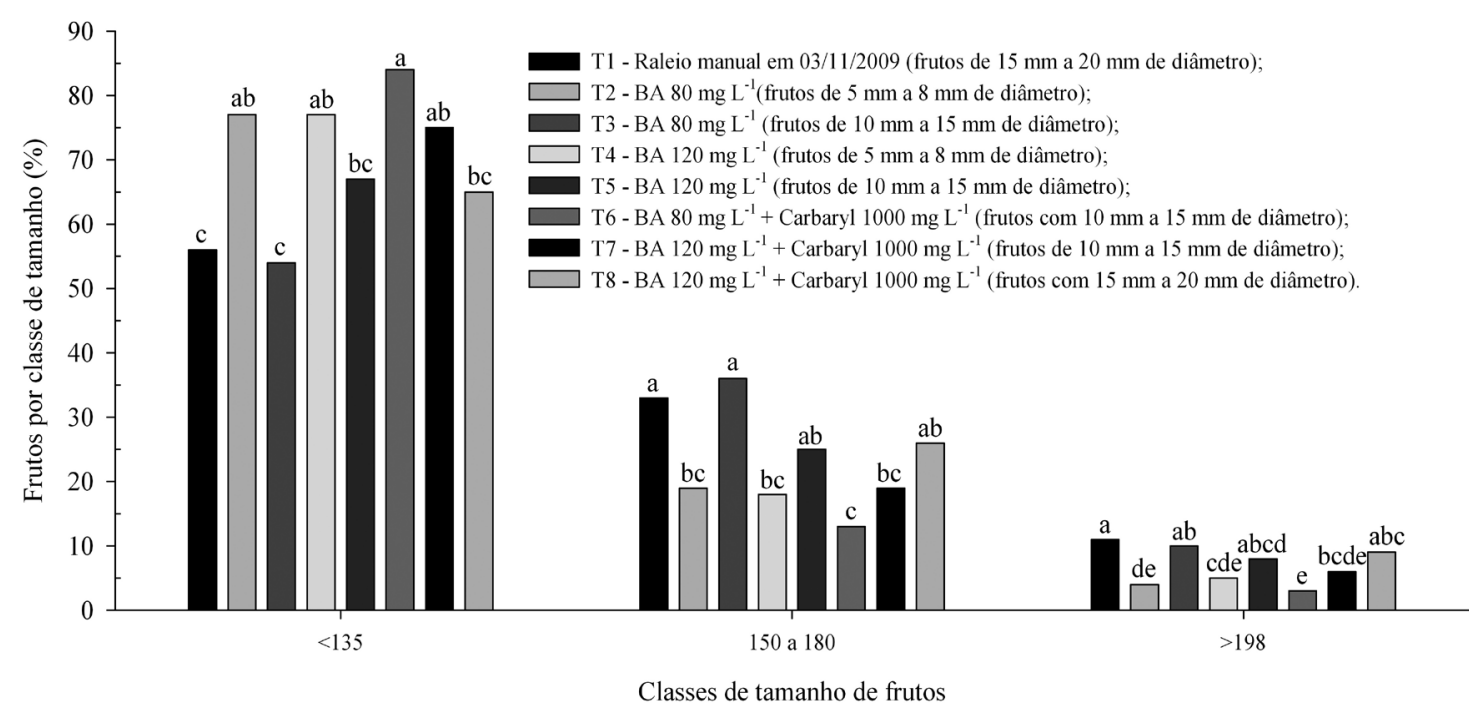

FIGURA 1 - Porcentagem média de frutos por classe de tamanho em macieiras 'Fuji Suprema', enxertadas sobre o porta-enxerto Marubakaido com interenxerto de M-9, em função de tratamentos de raleio. Fraiburgo-SC, 2010. Médias seguidas de mesma letra não diferem entre si, pelo teste de Tukey, a $5 \%$ de probabilidade. 


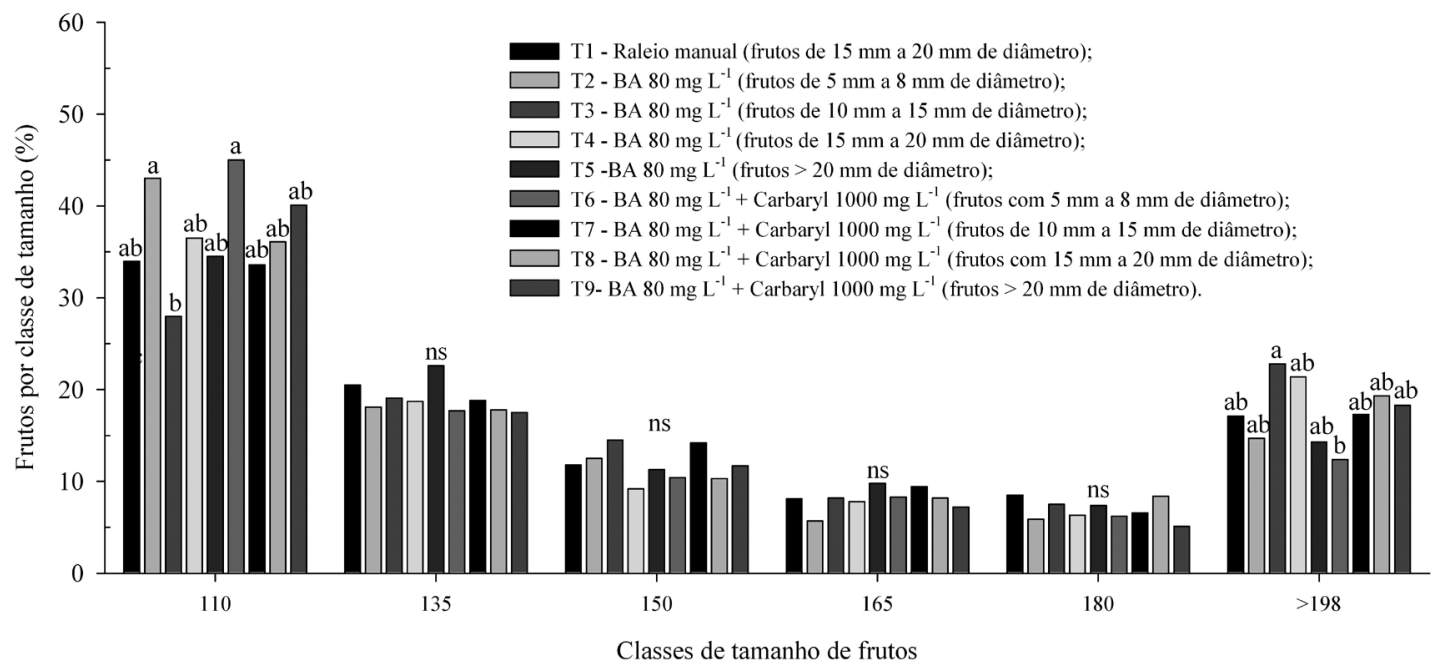

FIGURA 2 - Porcentagem de frutos por classe em macieiras 'Fuji Suprema', enxertadas sobre o porta-enxerto M-7, em diferentes tratamentos de raleio. Caçador-SC, 2010. Médias seguidas de mesma letra não diferem entre si, pelo teste de Tukey, a $5 \%$ de probabilidade. ns - não significativo não significativo pelo teste $\mathrm{F}(\mathrm{p}<0,05)$.

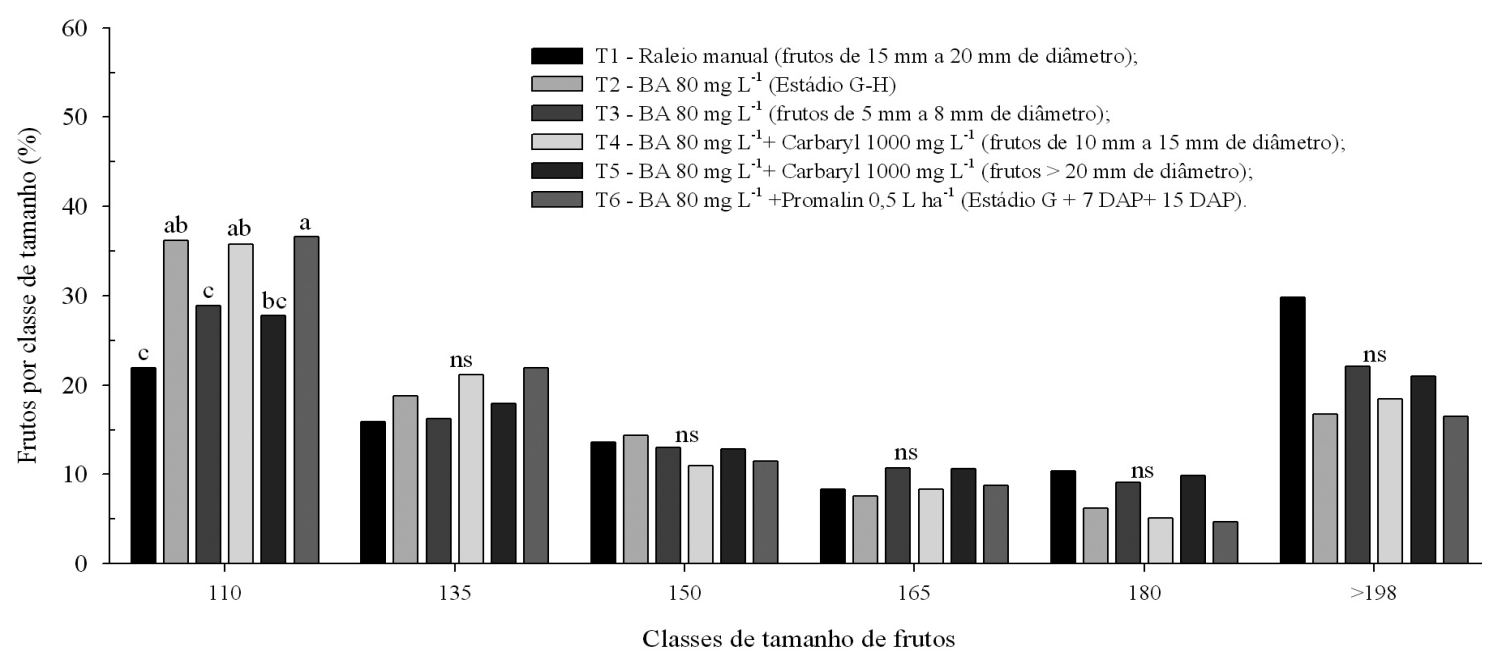

FIGURA 3 - Porcentagem de frutos por classe de tamanho em macieiras 'Fuji Suprema', enxertadas sobre o porta-enxerto M-26, em função de diferentes tratamentos. Caçador-SC, 2010. DAP - dias após a primeira aplicação de Promalin ${ }^{\circledR}$. Médias seguidas de mesma letra nãodiferen entre si, pelo teste de Tukey, a 5\% de probabilidade. ns- não significativo pelo teste $\mathrm{F}$. $(\mathrm{p}<0,05)$. 


\section{CONCLUSÕES}

1-A aplicação de benziladenina é uma alternativa viável para o raleio da macieira 'Fuji Suprema' e 'Lisgala'.

2-Concentrações mais elevadas de benziladenina são mais efetivas no raleio.

3-Há redução na efetividade da aplicação de benziladenina em frutos com diâmetro superior a 10 mm em comparação à aplicação em frutos menores.

4- A concentração de benziladenina aplicada pode ser diminuída quando em mistura com o carbaryl, sem comprometimento do efeito raleante.

\section{REFERÊNCIAS}

AMBROŽIČ TURK, B.; STOPAR, M. Effect of 6-benzyladenine application time on apple thinning of cv. 'Golden Delicious' and cv. 'Idared'. Acta Agriculturae Slovenica, Ljubljana, v. 95, n. 1, p. 69- 73, 2010.

BERTIN, N.; GAUTIER, H.; ROCHE, C. Number of cells in tomato fruit depending on fruit position and source-sink balance during plant development. Plant Growth Regulation, Dordrechet, v. 36, n. 2, p. 105-112, 2002.

BYERS, R. E.; CARBOUGH, D. H. Effect of the chemical thinning sprays on the apples fruit set. HortTechnology, Alexandria, v.1, p. 41-48, 1991.

COSTA, G.; BONANY, J.; CARBO, J.; CASALS, M.; STOPAR, M.; LAFER, G.; DORIGONI, A.; VIZZOTTO, G.; BOMBEN, C. Multilocation analysis of ats and ba thinning efficacy on 'Golden Delicious'. Acta Horticulturae, Wageningen, v. 636, p. 303-310, 2004.

COSTA, G.; DAL CIN, V.; RAMINA, A. Physiological, molecular and practical aspects of fruit abscission. Acta Horticulturae, Wageningen, v. 727, p. 301-310, 2006.

DENNIS, F.G. Mechanisms of action of apple thinning chemicals. HortScience, Alexandria, v. 37, n. 3, p. 471-474, 2002.
EDGERTON, L.J.; WILliAMS, M. Chemical thinning of apples. In: Tree fruit growth regulators and chemical thinning. Washington: State University, 1981. p. 147-172.

EPAGRI. A cultura da macieira. Florianópolis, 2006. 743p

GREENE, D.W.; AUTIO, W.R. Evaluation of benzyladenine as a chemical thinner on 'McIntosh' apples. Journal of the American Society for Horticultural Science, Alexandria, v.114, p. 6873, 1989.

GREENE, D. W.: AUTIO, W. R.; ERF, J. A.; ZHONGYUAN, Y. M. Mode of action of benzyladenine when used as a chemical thinner on apples. Journal of the American Society for Horticultural Science, Alexandria, v.117, p.775$779,1992$.

GREENE, D. Chemicals, timing and environmental factors involved in thinner efficacy on apple. HortScience, v. 33, n. 3, p. 477-481, 2002.

GREENE, D.W. Effects of repeated yearly application of chemical thinners on 'McIntosh' Apples. HortScience, Alexandria, v. 40, n.2, p.401403, 2005.

GUAK, S.; KIM, E.; KOOK, J. MaxCel as a postbloom for 'Hongro' and 'Fuji' apples. Horticultural Environment Biotechnology, Jangan-gu, v.3, n. 50, p. 181-187. 2009.

HAMADA, K.; HASEGAWA, K.; KITAJIMA, A.; OGATA, T. The relationship between fruit size and cell division and enlargement in cultivated and wild persimmons. Journal of Horticultural Science \& Biotechnology, Asford, v. 83, n. 2, p. 218-222, 2008.

MACHADO, A. A.; CONCEIÇÃO, A. R. Sistema de análise estatística para Windows. Winstat. Versão 2.0. Pelotas: UFPel, 2003.

MADAIL, R.H.; HERTER,F.G.; LEITE,G.B.; PETRI, J.L. Influence of flower structure in the production and fruit set in some apple cultivars. Acta Horticulturae, Wageningen, n. 872, p.309312,2010 . 
MELAND, M. Response of 'Victoria' Plums to Chemical Bloom Thinning. Acta Horticulturae, Wageningen, v. 636, p.275281, 2004.

NACHTIGALL, G.R. Estruturas de frutíferas na qualidade de maçãs, cultivares Gala e Fuji. 2000. $57 \mathrm{f}$. Tese (Doutorado em Agronomia-Fruticultura de Clima Temperado) - Faculdade de Agronomia Eliseu Maciel, Universidade Federal de Pelotas, Pelotas, 2000.

PETRI, J.L.; LEITE. G.B.; BASSO, C. Chemical thinning of 'Fuji' apples growing in mild winter climate. Acta Horticulturae, Wageningen, v. 727, p. 429-436, 2006.

ROBINSON, T.L.; LAKSO, A.N. Between Year and Within Year Variation in Chemical Fruit Thinning Efficacy of Apple during Cool Springs. Acta Horticulturae, Wageningen, v. 636, p. 283-294, 2004.
STOPAR, M., LOKAR, V. The effect of ethephon, NAA, BA and their combinations on thinning intensity of 'Summered' apples. Journal of Central European Agriculture, Plovdiv, v. 4, p. 399-403, 2003.

STOVER, E.; DAVIS, K.; WIRTH, F. Economics of fruit thinning: A review focusing on apple and citrus. HortTechnology, Alexandria, v. 14, p. 282 289, 2004.

VALENT BIOSCEINCES. Promalin ${ }^{\circledR}$. Disponível em: <http://www.valentbiosciences.com> Acesso em: 25 jan. 2012.

YUAN, R.; GREENE, D.W. Benzyladenine as chemical thinner for 'McIntosh' apples. I. Fruit thinning effect and associated relationship with photosynthesis, assimilate translocation, and nonstructural carbohydrates. Journal of American Society for Horticultural Science, Alexandria, $n$. 125, p. 169-176, 2000. 